\title{
Distribution of Acetyl Group in Cellulose Acetate as Determined by Nuclear Magnetic Resonance Analysis
}

\author{
Tsuyoshi SEI, Kazuki Ishitani, Ryoshu SuzUKI, \\ and Kiyoshi IKEMATSU \\ Research Center, Daicel Chemical Industries, Ltd., \\ 1239 Shinzaike, Aboshiku, Himeji, Hyogo 671-12, Japan
}

(Received July 31, 1984)

\begin{abstract}
KEY WORDS Cellulose Acetate / Acetyl Distribution $/{ }^{13} \mathrm{C}$ Nuclear Magnetic Resonance /
\end{abstract}

Goodlett et al. ${ }^{1}$ have developed a nuclear magnetic resonance (NMR) method for determining the distribution of acetyl groups in cellulose acetates. This method makes use of acetyl methyl proton spectra. On the other hand, Kamide and Okajima ${ }^{2}$ have used ${ }^{13} \mathrm{C}$ NMR spectra of $O$-acetyl carbonyl carbons.

In the latter work, the ${ }^{13} \mathrm{C}$ NMR spectra provide relative values of the degree of substitution (DS) for $O$-acetyl groups attached to the C-2, C-3, and C-6 carbons in the anhydroglucose (AHG) unit (see Figure 1). To obtain their absolute values, Kamide and Okajima determined the total DS by chemical analysis. We have recently found that, without the aid of chemical analysis, the ${ }^{13} \mathrm{C}$ NMR spectra of ring carbons in cellulose acetate can provide quantitative information on the distribution of $O$-acetyl groups at three different positions in the AHG unit.

In this work, on the basis of our tentative

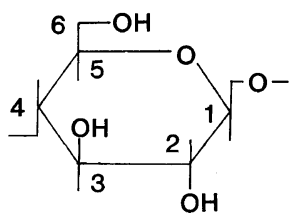

Figure 1. An anhydroglucose (AHG) unit. assignment for ring carbon, a ${ }^{13} \mathrm{C}$ NMR study was carried out for the quantitative assay of the distribution of acetyl groups of commercially available cellulose acetates with different DS values. To affirm the validity of our assignment of the ring carbon spectra, two methods were adopted, one being ${ }^{1} \mathrm{H}$ NMR method developed by Goodlett et al., ${ }^{1}$ while the other being gas chromatography (GC) by Björndal et al. ${ }^{3}$

\section{EXPERIMENTAL}

\section{Polymer Samples}

The samples were commercially available cellulose acetates manufactured by Daicel Chemical Industries, Ltd. The cellulose triacetate (CTA, DS $=2.92$ ) was prepared through an acetic anhydride-acetic acid-sulfuric acid reaction system. CTA was hydrolyzed to yield two samples of cellulose acetates, CMA $(\mathrm{DS}=1.75)$ and CDA $(\mathrm{DS}=2.41)$. In order to ascertain DS values determined by our proposed method, the DS was also determined by chemical analysis. In this analysis, the sample was hydrolyzed with sodium hydroxide followed by acidification with an excess of hydrochloric acid. The solution was then 
backtitrated with sodium hydroxide.

${ }^{13} \mathrm{C}$ and ${ }^{1} \mathrm{H} N M R$

The ${ }^{13} \mathrm{C}$ NMR spectra were recorded on a JEOL GX-270 spectrometer operating at $67.8 \mathrm{MHz}$ in ${ }^{1} \mathrm{H}$ decouple mode. All the spectra were obtained for $10 \%(\mathrm{w} / \mathrm{v})$ solution in DMSO- $d_{6}$ at $120^{\circ} \mathrm{C}$ by using a sample tube of $10 \mathrm{~mm}$ in its outer diameter. The spectra were accumulated for 5,000 pulses by using $16,000 \mathrm{~Hz}$ spectral width, a pulse repetition time of $1.5 \mathrm{~s}$, a flip angle of $45^{\circ}$, and $32 \mathrm{~K}$ data points. Chemical shifts were measured with respect to that of central peak of the methyl carbon of DMSO- $d_{6}$ which was taken as $39.7 \mathrm{ppm}$ downfield from tetramethylsilane. A gated decouple mode ${ }^{4}$ without nuclear Overhauser effect (NOE) was operated to ascertain if our spectral conditions would allow quantitative measurements.

The $270 \mathrm{MHz}{ }^{1} \mathrm{H}$ NMR spectra were obtained for $2 \%(\mathrm{w} / \mathrm{v})$ solution in chloroform- $d$ at $25^{\circ} \mathrm{C}$. The chemical shifts were measured with respect to the tetramethylsilane as a reference.

\section{Derivation of the Sample for GC Analysis}

The derivation of cellulose acetates was performed as follows: The reaction of cellulose acetates with methyl vinyl ether was carried out in $N, N^{\prime}$-dimethylformamide with $p$ toluenesulfonic acid as a catalyst. After completion of the reaction, the $p$-toluenesulfonic acid was neutralized with potassium carbonate. The mixture was filtered and the filtrate was evaporated to dryness. The methylation of the product was performed by Hakomori procedure. ${ }^{5}$ The product was dialyzed and then hydrolyzed. The mixture of methylated sugars was analyzed by GC as their alditol acetates. The separation was carried out on $3 \%$ Silar 10C $(2 \mathrm{~m})$ connected with $5 \%$ OV-17 $(2 \mathrm{~m})$ column at a helium flow rate of $60 \mathrm{ml}$ per minute. The column temperature was programmed from 210 to $250^{\circ} \mathrm{C}$ at an elevating rate of $1 \mathrm{~K} / \mathrm{min}$.

\section{RESULTS AND DISCUSSION}

\section{${ }^{13} C N M R$}

Presented in Figure 2 are the $67.8 \mathrm{MHz}$ proton decoupled ${ }^{13} \mathrm{C}$ NMR spectra of the samples of cellulose acetates, CMA (DS $=1.75)$ (a), CDA (DS = 2.41) (b), and CTA (DS = 2.92) (c). The signals in the spectral region of 58$63,70-80$, and $98-103 \mathrm{ppm}$ may belong to those of C-6, C-2-C-5, and C-1 carbons, respectively, with reference to the spectra of cellulose $^{6}$ and cellulose triacetate ${ }^{7}$ (Figure 2). It is evident that the relative signal intensity of C6 $(59.0 \mathrm{ppm})$ decreases as the total DS values increase, while in turn that of $\mathrm{C}^{\prime}(62.0 \mathrm{ppm})$ increases. Thus, the peaks of $\mathrm{C}^{\prime}{ }^{\prime}$ and $\mathrm{C} 6$ were assigned to C-6 carbons in substituted and unsubstituted glucose residues at C-6 position. The downfield shift of $\alpha$-carbon caused by acetylation of primary hydroxyl group may be supported from the ${ }^{13} \mathrm{C}$ NMR study of Gast ${ }^{6}$ and others. ${ }^{7}$

The intensities of $\mathrm{Cl}^{\prime}$ and $\mathrm{C}^{\prime}$ increase as the total DS values increase, while those of $\mathrm{Cl}$

Table I. Evaluation of the distribution of DS in the varieties of cellulose acetates

\begin{tabular}{|c|c|c|c|c|c|}
\hline \multirow{2}{*}{$\begin{array}{l}\text { Sample } \\
\text { code }\end{array}$} & \multirow{2}{*}{ Method } & \multicolumn{4}{|c|}{$\begin{array}{l}\text { DS of } O \text {-acetyl group } \\
\text { at each position }\end{array}$} \\
\hline & & C-2 & C-3 & C-6 & Total \\
\hline \multirow{5}{*}{ CMA } & $\operatorname{Titrn}^{\mathrm{a}}$ & - & - & - & 1.75 \\
\hline & ${ }^{13} \mathrm{C} \mathrm{COM}^{\mathrm{b}}$ & 0.60 & 0.55 & 0.58 & 1.73 \\
\hline & ${ }^{13} \mathrm{CNNE}^{\mathrm{c}}$ & 0.59 & 0.56 & 0.59 & 1.74 \\
\hline & ${ }^{1} \mathrm{H}$ & 0.59 & 0.56 & 0.59 & 1.74 \\
\hline & GC & 0.60 & 0.60 & 0.59 & 1.79 \\
\hline \multirow{5}{*}{$\mathrm{CDA}$} & Titrn & - & - & - & 2.41 \\
\hline & ${ }^{13} \mathrm{C} \mathrm{COM}$ & 0.84 & 0.83 & 0.72 & 2.39 \\
\hline & ${ }^{13} \mathrm{C}$ NNE & 0.84 & 0.84 & 0.73 & 2.41 \\
\hline & ${ }^{1} \mathrm{H}$ & 0.86 & 0.82 & 0.73 & 2.41 \\
\hline & GC & 0.83 & 0.83 & 0.71 & 2.37 \\
\hline \multirow{2}{*}{ CTA } & Titrn & - & - & - & 2.92 \\
\hline & ${ }^{13} \mathrm{C} \mathrm{COM}$ & 1.00 & 1.00 & 0.90 & 2.90 \\
\hline
\end{tabular}

a Chemical analysis by titration.

b Proton decoupled mode with NOE.

c Proton decoupled mode without NOE. 

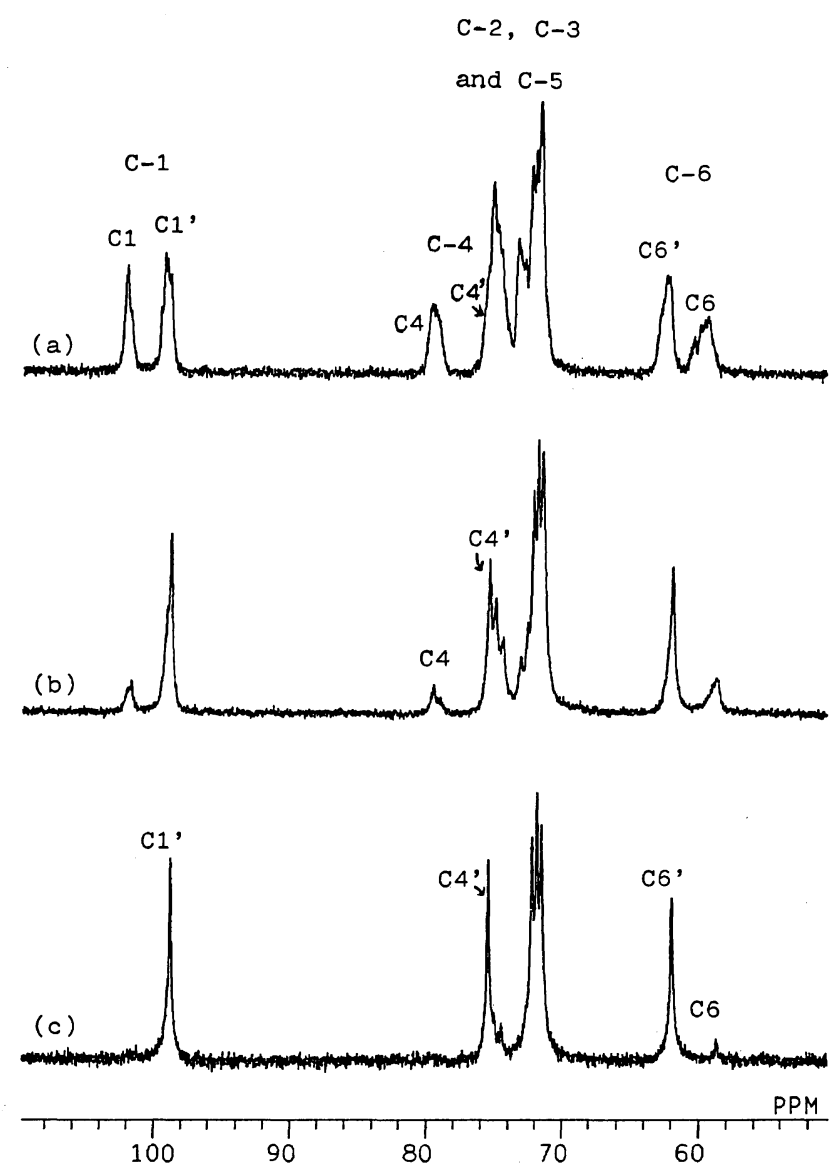

Figure 2. ${ }^{13} \mathrm{C}$ NMR spectra of cellulose acetate samples at $67.8 \mathrm{MHz}$. (a) CMA (DS=1.75); (b) $\mathrm{CDA}(\mathrm{DS}=2.41)$; (c) CTA (DS $=2.92)$.

and $\mathrm{C} 4$ decrease. Therefore, it may be expected that acetylation of the hydroxyl groups causes upfield shift of $\mathrm{Cl}$ and $\mathrm{C} 4$ carbons to $\mathrm{C}^{\prime}{ }^{\prime}$ and $\mathrm{C}^{\prime}$. It has been proposed $^{8,9}$ that the acetylation of hydroxyl groups in carbohydrates results in an upfield shift $(2-3 \mathrm{ppm})$ of $\beta$ carbon signal ( $\beta$-effect), while a chemical shift of $\gamma$-carbon is insignificantly effected $(<0.3$ ppm). Therefore, the peaks of $\mathrm{Cl}$ (101.9 ppm) and $\mathrm{Cl}^{\prime}$ (98.9 ppm) were assigned to be the acetal carbons in unsubstituted and substituted glucose residues at C-2 position, respectively. Similarly, the signals of $\mathrm{C} 4$ (79.6 ppm) and $\mathrm{C}^{\prime}$ (75.4 ppm) were attributed to the C-4 carbons in unsubstituted and substituted ones at C-3. In the samples of CMA and CDA, the resonance peak of $\mathrm{C}^{\prime}$ overlaps with the peaks corresponding to C-2, $\mathrm{C}-3$, and $\mathrm{C}-5$ carbons. The nuclear Overhauser effects (NOE) for C-1 to C-6 carbons were almost the same in our spectral conditions, so that we can estimate quantitatively the absolute DS values at C-2, C-3, and C-6 positions in the AHG unit. The sum of each refers to the total DS. The results obtained are shown in Table I.

\section{${ }^{1} H N M R$ and $G C$}

In order to affirm the validity of our assignments on the ${ }^{13} \mathrm{C}$ NMR spectral analysis, ${ }^{1} \mathrm{H}$ NMR method of Goodlett et al. ${ }^{1}$ and GC 


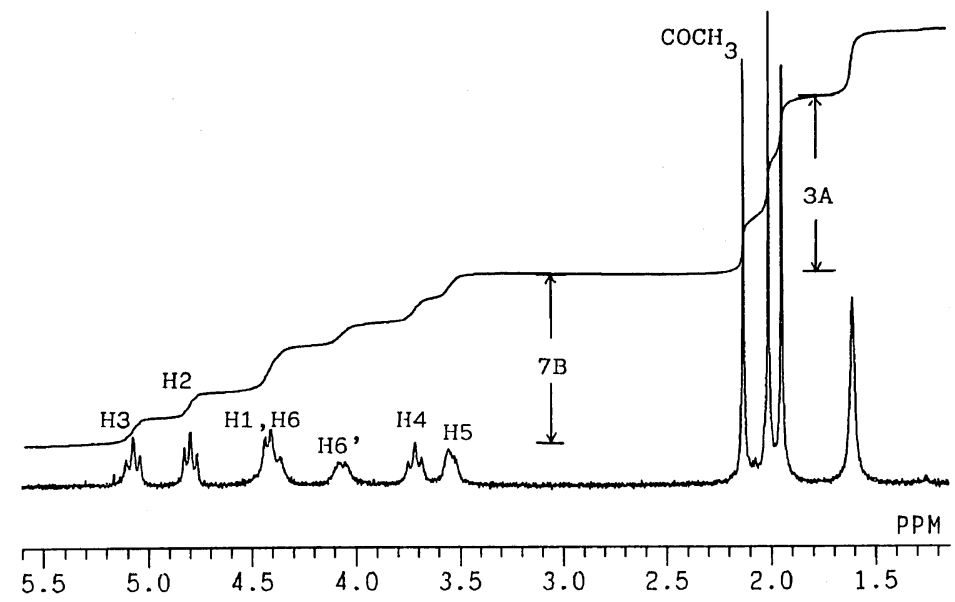

Figure 3. ${ }^{1} \mathrm{H}$ NMR spectra of CDA. The sample for ${ }^{1} \mathrm{H}$ NMR was acetylated with acetyl- $d_{3}$ chloride.

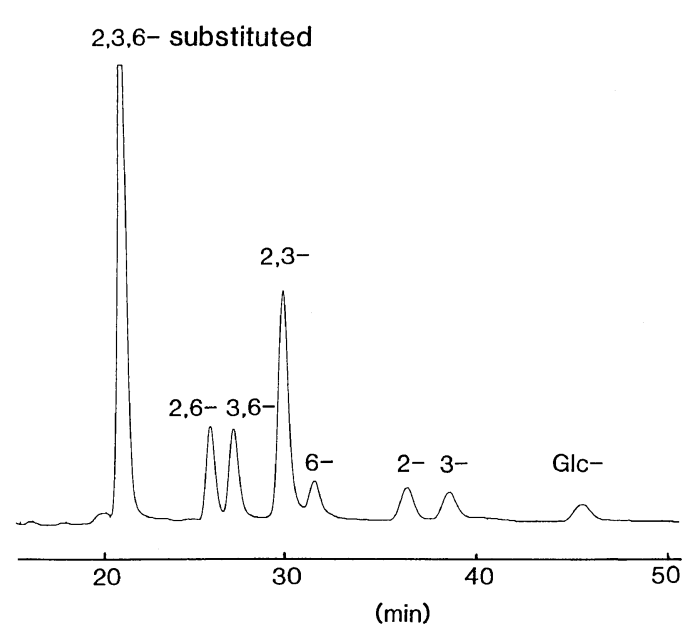

Figure 4. GC chromatogram of methylated alditol acetates from CDA.

by Björndal et al. ${ }^{3}$ were employed. The ${ }^{1} \mathrm{H}$ NMR spectra can be obtained by complete acetylation of the free hydroxyl groups in cellulose acetates with perdeuterated acetyl$d_{3}$ chloride. $^{1}$. The obtained spectra of CDA is shown in Figure 3. Three distinguishable peaks at $2.13,2.01$, and $1.95 \mathrm{ppm}$ were already assigned to the $O$-acetyl methyl protons attached to C-6, C-2, and C-3 carbons, ${ }^{1}$ respectively. The total DS is readily obtained from a ratio of two spectral integrals, $\mathrm{A} / \mathrm{B}$, where $\mathrm{A}$ is one-third of the peak area of three $O$-acetyl methyl proton signals, whereas $B$ is one-seventh of the integral of the ring proton signals between 3.5 and $5.2 \mathrm{ppm}$. The distribution of $O$-acetyl groups can be calculated from the total DS and the peak area ratio of individual acetyl methyl protons.

A gas chromatogram of methylated alditol acetates is shown in Figure 4. The separation was performed on Silar 10C connected with OV-17 column. This column gives us almost complete separation, so that it would be superior to the OV-225 and ECNSS-M columns ${ }^{3}$ previously used.

\section{Comparison of Our ${ }^{13} C$ NMR with Other Methods Studied}

Table I shows the DS values of $O$-acetyl groups at each position of three different samples, CMA, CDA, and CTA, obtained by three different analytical methods. The data by chemical analysis was also included. It is obvious from the Table I that the DS values at each position obtained by our ${ }^{13} \mathrm{C}$ NMR method are in good agreement with those from ${ }^{1} \mathrm{H}$ NMR and GC. The total DS were obtained from the sum of each value. Note that the data of the total DS are also in good agreement 
with each other.

It can be therefore concluded that the procedure by ${ }^{13} \mathrm{C}$ NMR method described in this paper provides a reliable way of determining the distribution of $\mathrm{O}$-acetyl group of cellulose acetates.

\section{REFERENCES}

1. V. W. Goodlett, J. T. Dougherty, and H. W. Patton, J. Polym. Sci., A-1, 9, 155 (1971).

2. K. Kamide and K. Okajima, Polym. J., 13, 127
(1981).

3. H. Björndal, B. Lindberg, and K.-G. Rosell, J. Polym. Sci., C, 36, 523 (1971).

4. R. Freeman, J. Chem. Phys., 53, 457 (1970).

5. S. Hakomori, J. Biochem. (Tokyo), 55, 205 (1964).

6. J. C. Gast, R. H. Atalla, and R. D. MaKelvey, Carbohydr. Res., 84, 137 (1980).

7. B. Capon, D. S. Rycroft, and J. W. Thomson, Carbohydr. Res., 70, 145 (1979).

8. A. S. Shashkov, A. F. Sviridov, O. S. Chizhov, and P. Kováč, Carbohydr. Res., 62, 11 (1978).

9. E. E. Lee and J. O. Wood, Carbohydr. Res., 89, 329 (1981). 